\title{
On the Risk of Being a Cultural Chameleon: Variations in Collective Self-Esteem Across Social Interactions
}

\author{
MICHELLE DOWNIE \\ McGill University \\ GENEVIEVE A. MAGEAU \\ Université de Montréal \\ RICHARD KOESTNER \\ TONE LIODDEN \\ McGill University
}

\begin{abstract}
In the present study the authors used an event-contingent daily recording strategy, the Rochester Interaction Record, to examine the relation of perceived evaluations of a multicultural person's heritage group to the nature and quality of his or her social interactions. Hierarchical linear modeling showed that having an interaction partner who positively evaluated one's heritage culture was associated with significantly enhanced interaction intimacy, disclosure, and quality, as well as with feelings of personal acceptance. Moderator analyses revealed that individuals who possessed a chameleon-like cultural identity and those who had low public collective self-esteem were particularly reactive to how their heritage group was being evaluated.
\end{abstract}

Keywords: interaction record, collective self-esteem, sociometer theory, cultural chameleonism

The primary purpose of identities, including cultural identities, is to maintain, secure, and cement a person's connection to social groups (Ryan \& Deci, 2002). Through a process of internalization individuals strive to autonomously identify with the norms and

- Michelle Downie, Richard Koestner, and Tone Liodden, Department of Psychology, McGill University; Genevieve A. Mageau, Department of Psychology, Université de Montréal.

This study was funded by grants from the Social Science and Humanities Research Council of Canada and the Fonds pour la Formation de Chercheurs et l'Aide a la Recherche, Quebec to R. Koestner.

Correspondence concerning this article should be addressed to Michelle Downie, Department of Psychology, McGill University, 1205 Dr. Penfield Ave. Montreal, QC, Canada, H3A 1 B1. E-mail: mdownie@ego.psych.mcgill.ca 
values of the culture into which they are primarily socialized (Chirkov, Ryan, Kim, \& Kaplan, 2003). This cultural internalization process is complicated for immigrants, who must find ways to internalize the guidelines of secondary, and even tertiary, cultural identities and simultaneously find ways to integrate these sometimes seemingly disparate identities (Downie, Koestner, ElGeledi, \& Cree, 2004).

In Canada the proportion of the population that was born outside the country, as of the 2001 census, was the highest that it had been in 70 years at $18.4 \%$ "CCensus of Population," 2003, January 21). At the same time as the immigration rates are rising, the source countries are also changing. Traditionally, the vast majority of immigrants to Canada were from European nations such as the United Kingdom, Italy, Germany, and the Netherlands. Since the 1990s, however, these patterns have reversed such that only about $20 \%$ of immigrants are now coming from Europe, whereas $58 \%$ are arriving from Asia and the Middle East ("Census of Population," 2003, January 21). At these rates it is projected that by 2017 one of every five people in Canada will be a visible minority (Study: Canada's Visible Minority Population, 2005). This shift is also evident in the United States where, in 1999, $75 \%$ of immigrants were visible minorities ("Census Figures Show," 2000, August 30). Thus, the number of people who find themselves in the position of negotiating multiple, potentially disparate, cultural identities is growing rapidly.

The present study was focused on examining the social experiences of multicultural individuals. For the purposes of this study a multicultural person refers to an immigrant or ethnic minority who identifies a heritage culture that is distinct from the dominant host culture. Such individuals are expected to have learned, to varying degrees of proficiency, at least two distinct behavioral responses that enable them to competently interact within the context of their heritage culture and their host culture. In this study we assess how the perceived evaluation of a multicultural indi- vidual's heritage culture influences his or her daily social interactions. Specifically, we examine how an identity designed to meet one's need for relatedness may, at times, become a barrier to relatedness.

\section{Personal and Collective Self-Esteem as a Sociometer}

Memberships in social groups are desirable to the extent that they foster positive relations with others. The need to relate to others and to feel that one belongs is widely accepted as universal (Baumeister \& Leary, 1995; Deci \& Ryan, 2000). According to sociometer theory this need is so central that what we perceive as self-esteem is nothing more than an evaluative judgment of how desirable a person feels they are as a group member or relationship partner (for a review, see Leary \& Baumeister, 2000). In other words, self-esteem is a sociometer that detects changes in the extent to which a person is being accepted or rejected by relevant others in their social environment. Thus, when self-esteem is high, this is a reflection that an individual is accepted and valued in their relationships and in the social groups to which they belong. Alternatively, the experience of low self-esteem is functionally important to the extent that it brings to the individual's attention the possibility that they may be rejected, thereby alerting the person of the necessity to do something about it. Thus, according to sociometer theory, the self-esteem motive exists not to maintain self-esteem but rather to minimize the possibility of rejection and ostracism (Leary, 1999). Therefore, self-esteem tends to be more strongly related to how a person perceives that others are evaluating him or her rather than to what may be considered more objective indicators of the person's ability or worth (Leary \& Baumeister, 2000).

If personal self-esteem is derived from a person's desirability as a member of a social 
group, then one may reasonably ask what role does the perceived desirability of this social group play in influencing a person's self-esteem and behavior? Indeed, given sociometer theory's explanation for the functional significance of personal self-esteem, it should follow that esteem for one's social groups should operate in much the same manner. Individuals' evaluation of their social groups should similarly serve as an indication that the group is valued, and members of the group are sought after and highly regarded. For this reason, in the present study we ask participants to indicate how they feel they are personally being appraised and further ask them to rate how their heritage culture is being appraised by their interaction partner to consider the effects of the sociometer on the characteristics of their interactions.

The effects of esteem for one's social groups has been examined in a separate line of research. Crocker and Luhtanen (1990) argued that just as individuals differ in their personal self-esteem, they may also differ in terms of their collective self-esteem (CSE), or in other words, how they evaluate the social groups they belong to. Based on social identity theory, Luhtanen and Crocker (1992) proposed that two of the key components of CSE are how persons privately evaluate their social group and how they feel their social group is publicly evaluated. Research into the effects of CSE showed that, for samples of White, Black, and Asian university students in the United States, CSE was positively related to psychological adjustment (Crocker, Luhtanen, Blaine, \& Broadnax, 1994). This relationship was still significant for the Black and Asian subsamples when personal self-esteem was partialed out. Thus, CSE is associated with minorities' overall well-being, independent of feelings of personal esteem. In the present study we assess feelings of collective and personal self-esteem in the context of social interactions. It is expected that how one's group is evaluated will influence how the individuals feels they are personally being evaluated and how they behave in the interaction.

In applying sociometer theory to CSE in the context of social interactions, the public dimension of this scale may best reflect a sociometer. The impression that one's heritage culture is being positively or negatively evaluated by one's interaction partner, or in sociometer terms, that one's culture is being accepted or rejected, is expected to influence the intimacy, disclosure, quality, and how one feels one is personally evaluated in an interaction. For example, consider a multicultural university student interacting with a fellow student. This fellow student could be a member of the dominant culture, a member of another minority culture, or someone from the same heritage culture. If the student perceives that his or her interaction partner has unfavorable views of his or her heritage cultural identity, this perception may have an impact on how the interaction unfolds. For instance, the student may attempt to protect against this perceived rejection by interacting in a guarded, impersonal manner. No doubt, he or she will also perceive the interaction as unpleasant and may feel that not only his or her heritage culture has been rejected, but that he or she has been personally rejected by extension.

It is expected that the detrimental effects of a negative evaluation of one's heritage culture will be independent of whether one is interacting with someone from outside one's heritage culture or someone within one's heritage culture. Indeed, the evaluation of an interaction partner of the same heritage culture may be expected to vary (because of individual differences in CSE and identification), and it may be particularly impactful if someone from one's own heritage culture seems to view the culture negatively. Thus, whether one's heritage culture is positively or negatively received in an interaction is expected to influence the manner in which multicultural persons interact, the quality of that interaction, and how they feel about themselves. Moreover, it 
seems likely that the direct effect of how one's heritage culture is evaluated in the course of one's interactions may be moderated by the dispositional tendency to see one's heritage culture as generally valued and respected (i.e., public CSE).

\section{Negotiating Multiple Cultural Identities}

A further factor may influence individuals' propensities to be more reactive to how their cultural group is evaluated. In the context of social interactions this reactivity would involve altering their social behavior in response to whether they perceive their cultural group to be accepted or rejected by interaction partners. Specifically, we hypothesized that how an individual manages his or her multiple cultural identities will moderate the effects of heritage rejection on the qualities of the person's social interactions. For immigrants and ethnic minorities the preferred and most adaptive strategy for managing their heritage and host culture seems to be adopting a bicultural identity (LaFromboise, Coleman, \& Gerton, 1993). However, it is now recognized that even a bicultural identity can be differentially enacted (Roccas \& Brewer, 2002). The empirical literature on this relatively recent conceptualization has tended to be focused on whether the individuals perceive their dual (or multiple) cultural identities as compatible or oppositional (Benet-Martinez, Leu, Lee, \& Morris, 2002; Downie et al., 2004; Haritatos \& Benet-Martinez, 2002). Achieving a compatible identity would require individuals to mindfully consider how their cultural identities relate to one another and integrate those cultures in such a way that they form a coherent sense of self (Ryan \& Deci, 2002). This does not preclude the possibility that such individuals may find themselves alternating their behavior in response to the context of a situation as the alternation model of biculturalism proposes. However, when alternation occurs, persons with an integrated, compatible cultural identity would not experience the same feelings of internal conflict and pressure to regulate their behavior as someone with an oppositional cultural identity. Thus, a person with a compatible cultural identity and a person with an oppositional identity may both find themselves in situations in which they are behaving in a respectful deferential manner with their elderly relatives and in a more raucous boisterous manner with their friends from the host culture. The fundamental difference is that the person with the compatible identity would feel comfortable while responding to the differing environments; whereas the oppositional person would attribute the differences in behavior to irresolvable cultural differences and would feel compelled to enact a particular role in each situation. In other words the compartmentalized individual may feel as though he or she is behaving in a chameleon-like manner.

Previous research has shown that individuals who adopt a compartmentalized or chameleon-like approach to managing their identities had decreased well-being compared with those who have integrated identities as indicated in both self reports and peer reports (Downie et al., 2004). Given the apparent risk of adopting such a strategy, it seemed important to consider why a person would behave in this manner. A recent study found that individuals who perceived that their parents were controlling with regard to their heritage culture (i.e., strictly enforced values, participation in heritage activities, and so forth) were more likely to become cultural chameleons (Downie \& Koestner, 2004). It appears that controlling parenting predisposes a person to orient toward whatever cultural demands are imposed on a situation. For these individuals the problem is not so much that their behavior may differ depending on the cultural context of the situation they are in, but rather that their cultural identities are not integrated in such a way that they can feel as though they are being themselves even when the situation requires them to exhibit different aspects of themselves (Shel- 
don, Ryan, Rawsthorne, \& Ilardi, 1997). In other words, behaving like a chameleon per se may not be as problematic as feeling like one is a chameleon.

The fact that cultural chameleons are consciously aware that they are altering their behavior suggests that they are worried that if they do not do so they may not receive the approval of those they are associating with at the time. Thus, chameleons may have lower public CSE compared with multicultural persons who have a more integrated identity. In terms of sociometer theory, this suggests that chameleon-like individuals are highly attuned to possible rejection based on cultural criteria. We anticipate that cultural chameleons will be highly reactive to the evaluation they perceive their interaction partner is making of their heritage culture. Thus, for people with a chameleon-like identity who feel like they are phenomenally different people in response to the cultural composition of a situation, their conception of themselves may be very closely connected to how their culture is being perceived by their interaction partner. We hypothesize that a cultural chameleons' willingness to behave intimately will be directly tied to how they believe their heritage culture is being evaluated. Indeed, the quality of their interactions and how they feel they are personally being evaluated will be directly tied to how they perceive their heritage culture is being appraised.

\section{Present Study}

The purpose of the present study was to examine the influence of heritage group evaluation on the daily interactions of multicultural individuals. Specifically, an eventcontingent daily recording strategy, the Rochester Interaction Record, was used to determine the relation of heritage evaluation to the nature and quality of multicultural individuals' social interactions. As a preliminary test of our hypotheses, we expected to find, using dispositional measures, that adopting a chameleon-like approach to managing one's multiple cultures would be associated with lower public CSE and reduced psychological well-being. In terms of social interactions, we hypothesized that interactions in which participants felt their heritage culture was positively evaluated would be experienced as more intimate, more disclosing, more personally validating, and more enjoyable. Furthermore, we anticipated that how persons negotiate their multicultural identity would influence the role of heritage evaluation in their social interactions. Adopting a chameleon-like approach and having lower public CSE were expected to predispose multicultural people to be more affected by the valence of their partner's evaluation of their heritage culture.

\section{Methods}

\section{Participants}

Ninety-eight persons belonging to various ethnic groups participated in the present study. Two individuals failed to indicate their heritage culture on the questionnaire and were excluded from all analyses. The remaining 96 individuals consisted of 32 males and 64 females, with a mean age of 20.2. Sixty-six percent of the participants were first-generation immigrants. The average number of years that they had been living in Canada was 5.7. Participants represented $>45$ different ethnic groups and were selected in roughly equal proportions from the following regional categories: subSaharan Africa; Middle East and North Africa; Eastern Europe; Western Europe; Latin America and Caribbean; East Asia and $\mathrm{Pa}-$ cific; and South Asia.

\section{Procedure}

Participants were recruited from a paid participant pool at a large English-speaking university in Montreal, Quebec, Canada. Respondents were paid $\$ 30$. Participants came 
into the laboratory to complete a self-report questionnaire consisting of demographic information as well as the scales described below. Upon completing the survey, participants were given detailed instructions on how to fill out the Rochester Interaction Record (RIR; Wheeler \& Nezlek, 1977). For 1 week following the initial laboratory session participants completed one record after every social interaction they had that lasted longer then $10 \mathrm{~min}$. Thus, each participant completed a unique number of interaction records depending on how many conversations they had over the course of 1 week. On average, participants completed 36.4 reports about their interactions at discrete time points throughout the week. At the end of this time period participants returned the completed records and were given the opportunity to ask questions, along with a debriefing sheet that provided them with more information on the study and an e-mail address to contact the researcher if they had any further questions or wished to know the results of the study.

\section{Research Materials}

RIR. The interaction record was event-contingent in that one record was to be completed for every social interaction the participants had that lasted $10 \mathrm{~min}$ or longer. Interactions could occur in person, over the phone, or via the Internet (i.e., chatting on-line; e-mailing did not qualify because it is not interactive). Participants were asked to complete each record as soon as possible after each interaction. We utilized a slightly modified version of the RIR (Wheeler \& Nezlek, 1977) to assess social interactions. Each record included the date, time, and length of the interaction, relationship with the interaction partner (e.g., friend, sibling), ethnicity of the partner, and language of the interaction. Participants rated the interactions on the following dimensions: intimacy, personal disclosure, partner disclosure, quality, heritage acceptance, and personal acceptance. These single-item measures were rated on 7-point Likert-type scales. Thus, when rating the intimacy of an interaction, participants would be asked to indicate where the interaction fell on a continuum ranging from 1 (superficial) to 7 (meaningful). For personal and partner disclosure participants were asked to rate each separately on a continuum from I/other disclosed 1 (very little) to 7 ( $a$ great deal). Quality of the interaction was assessed by asking participants to rate the interaction from 1 (unpleasant) to 7 (very pleasant).

The heritage acceptance item on the RIR asked participants to make an evaluative judgment of how their heritage culture was being perceived by their interaction partner. This heritage evaluation item reflects the public CSE dimension on Luhtanen and Crocker's (1992) CSE scale. Keeping in mind the premise of sociometer theory that esteem reflects an assessment that one is being accepted or rejected, participants were asked to make a valenced judgment about how their interaction partner's evaluation of their heritage culture impacted them. The interaction was rated on a 1 to 7 scale where one end indicated the interaction made me feel very poorly about my heritage culture, the midpoint, indicating that the discussion was neutral or had no bearing on how they felt about their heritage culture, was the interaction did not impact how I felt about my heritage culture, and on the other end the interaction made me feel very good about my heritage culture. Similarly, a second item assessed the personal acceptance in the interaction. Participants were instructed to make a valenced judgment of how they felt they personally were being evaluated by their partner. Based on the behavior of their partner participants rated the interaction on a 1 to 7 scale where one end of the scale indicated that the interaction made me feel very poorly about myself, the midpoint indicated that the interaction did not impact how I felt about myself, and the other end indicated that the interaction made me feel very good about myself. In this respect, participants were instructed to assess how their interaction partner was evaluating their culture and them personally. 
Demographic Information. Participants were asked to indicate their gender, age, ethnic identity, generational status, year of arrival in Canada, and the language spoken predominantly in their home.

Cultural Chameleonism. The purpose of this scale was to determine participants' perception of compatibility between their heritage culture and the dominant cultures and how they manage conflicts between cultural demands. This scale had previously been referred to as a measure of multicultural identity integration (Downie et al., 2004); however, to clearly distinguish it from the independently developed measure of bicultural identity integration (Benet-Martinez et al., 2002; Haritatos \& Benet-Martinez, 2002), we renamed the measure cultural chameleonism, as the items reflect the chameleonlike property of changing one's identity to fit one's cultural surroundings. The 15 -item scale asked participants about their perceptions of cultural disparity, the ease with which their cultures coexist, and their preferred strategy for interacting with individuals from each of the three cultures (i.e., separately or simultaneously). Sample items included "How I present myself changes based on the cultural context of a particular situation" and "I prefer to associate with my friends from different cultures separately." Participants rated the extent to which they agreed with each item; potential responses ranged from 1 (strongly disagree) to 9 (strongly agree). Cronbach's alpha was 0.79 .

CSE. Luhtanen and Crocker's (1992) 16item scale was used. The scale comprises four subscales: private, public, importance to identity, and membership. Respondents were asked to indicate the extent to which they agreed or disagreed with each statement on a 7-point scale that ranged from 1 (strongly disagree) to 7 (strongly agree). For the complete scale, Cronbach's alpha was .84. When the subscales were considered separately the alphas were $.92, .78, .80$, and .79 for private, public, importance, and membership, respectively. Although the complete scale was administered for the purposes of this study, our primary interest was in the public dimension of the scale, as this was the only dimension about which we had made specific hypotheses.

Psychological Well-Being. Ryff and Keyes' (1995) 18-item scale was used. The scale consists of three items for each of six dimensions. The six dimensions are personal acceptance, positive relations with others, autonomy, environmental mastery, purpose in life, and personal growth. Thus, for the wellbeing measure scores across each of the six dimensions were aggregated. Respondents were asked to indicate the extent to which they agreed with the statements on a 5-point scale ranging from 1 (strongly disagree) to 5 (strongly agree). Thus, the well-being measure was calculated by aggregating the scores across each of the six dimensions. Cronbach's alpha for the complete scale was 0.77 .

\section{Results}

\section{Overview of the Analyses}

The relations between the dispositional variables, cultural chameleonism, CSE, and psychological well-being, are presented first. Next, brief descriptives are provided for the interaction data, and the influence of heritage evaluation on the characteristics of a multicultural person's social interactions is examined. Specifically, at a within-person level, the influence of the perceived heritage evaluation on intimacy, disclosure, personal evaluation, and interaction quality is described. The possibility that either personal evaluation or the characteristics of the person with whom one is interacting are the driving force behind the effects of heritage evaluation is also considered. Finally, at the between-person level, the moderating effects of adopting a chameleon-like approach to managing one's cultural identity and hav- 
ing dispositionally high public CSE is examined.

\section{Preliminary Analysis}

Analyses were conducted to determine the relations between the dispositional measure of chameleonism and CSE and psychological well-being. Chameleonism was unrelated to the composite measure of CSE; however, it did relate to the public CSE subscale $(r=$ $-.30, p<.01$ ), such that participants who scored high on cultural chameleonism were more likely to indicate that they did not feel that their heritage culture was positively regarded by others. Additionally, chameleonism was significantly associated with reduced well-being $(r=-.25, p<.02)$. Thus, it appears that individuals who adopt a chameleon-like approach to managing their multiple cultures are also more likely to report that they feel their heritage culture is less positively regarded and that they personally have lower well-being.

\section{Central Analysis}

On average, participants reported having $36.4(S D=20.4)$ social interactions throughout the week. Of these interactions, $31 \%$ were conducted with ingroup members, whereas the remaining $69 \%$ were with outgroup members. Eighty-three percent of the interactions were with family members or friends, whereas $17 \%$ were with coworkers and acquaintances. The majority of the interactions were completed in English $(73.6 \%)$, whereas $16.3 \%$ occurred in the heritage language, $9.2 \%$ were in French, and $0.9 \%$ of the interactions were in some other language.

The interaction data are a hierarchically structured data set, in which repeated interaction measures (Level 1) are nested under participants' dispositional measures (Level 2). Thus, hierarchical linear modeling (HLM) with the restricted maximum likelihood method of estimation (Raudenbush \& Bryk, 2002) was chosen as the most appropri-
TABLE 1 Means and Standard Deviations for All Level 1 and Level 2 Variables With the Tricultural Sample

\begin{tabular}{lcc}
\hline Variables & $M$ & $S D$ \\
\hline Level 1 & & \\
$\quad$ Intimacy & 4.75 & 1.72 \\
$\quad$ Self-disclosure & 4.36 & 1.74 \\
Other disclosure & 4.66 & 1.64 \\
Quality & 5.72 & 1.19 \\
Heritage evaluation & 5.23 & 1.36 \\
$\quad$ Personal evaluation & 5.59 & 1.22 \\
Level 2 & & \\
$\quad$ Cultural chameleonism & 4.92 & 1.15 \\
$\quad$ Public collective self-esteem & 4.80 & 1.35 \\
& & \\
\hline
\end{tabular}

ate statistical analytic procedure for this type of data set (Nezlek, 2003). HLM analyses integrate the different levels of generality into one multilevel equation, allowing for the simultaneous but independent investigation of within- and between-person variability.

The means and standard deviations for all Level 1 and Level 2 variables are presented in Table 1. It can be seen that participants generally rated their interactions positively, especially in terms of quality and feelings of self-esteem. ${ }^{1}$

\section{Influence of Heritage Evaluation on the Outcome Measures}

As a first step, the unconditional models for each of the dependent variables were tested to determine how the between- and withinperson variance of each interaction outcome was partitioned. Intraclass correlations were calculated from the within- and between-person variance of the unconditional models (Raudenbush \& Bryk, 2002). Results showed that for each outcome, there was more variability between interactions than

\footnotetext{
${ }^{1}$ Given that our sample consisted of primarily first- and second-generation immigrants we conducted an initial $t$ test to determine whether generational status would influence participant's scores on the dispositional measures or on the mean characteristics of their social interactions. None of these tests were significant.
} 
between participants (i.e., intimacy, withinperson $=80.33 \%$ and between-person $=$ $19.67 \%$; personal disclosure, within-person $=$ $77.74 \%$ and between-person $=22.26 \%$; partner disclosure, within-person $=80.00 \%$ and between-person $=20.00 \%$; personal evaluation, within-person $=70.29 \%$ and betweenperson $=29.71 \%$; quality, within-person $=$ $83.02 \%$ and between-person $=16.98 \%$ ).

Next, we tested our hypotheses that a positive heritage evaluation would be associated with enhanced intimacy, disclosure, a positive personal evaluation, and quality of an interaction. During HLM analyses, all continuous Level 1 variables were centered on each participant's mean, whereas all Level 2 variables were centered on the sample mean (Raudenbush \& Bryk, 2002). Percentages of explained variance for each effect in the present article were calculated by comparing the within- and between-person variance before and after adding Level 1 and Level 2 predictors, respectively (Raudenbush \& Bryk, 2002, see Kreft \& de Leeuw, 1998, for other points of view).

Results showed that when heritage evaluation was positive, the interaction was rated as more intimate $\left[\gamma_{10}=.28, p<.001\right.$; grand mean for intimacy $\left.\left(\gamma_{00}\right)=4.79\right]$, and participants disclosed more $\left[\gamma_{10}=.28, p<\right.$ .001 ; grand mean for personal disclosure $\left.\left(\gamma_{00}\right)=4.38\right]$, perceived their interaction partner as more disclosing $\left[\gamma_{10}=.23, p<\right.$ .001 ; grand mean for partner disclosure $\left.\left(\gamma_{00}\right)=4.62\right]$, felt they were personally evaluated more positively $\left[\gamma_{10}=.35, p<.001\right.$; grand mean for personal evaluation $\left.\left(\gamma_{00}\right)=5.60\right]$, and enjoyed the interaction more $\left[\gamma_{10}=.37, p<.001\right.$; grand mean for quality $\left.\left(\gamma_{00}\right)=5.71\right]$. Heritage evaluation accounted for $5.67 \%$ of the variance in a participant's level of intimacy, $5.61 \%$ of personal disclosure, $4.89 \%$ of partner's disclosure, $14.46 \%$ of personal evaluation, and $13.90 \%$ of the variance in interaction quality. In sum, interactions in which one feels one's heritage culture is being positively evaluated are likely to be experienced as more intimate, more disclosing, more personally accepting, and more enjoyable.
It was important to determine whether the effects of heritage evaluation on the characteristics of the interactions could be accounted for by some third variable. In particular, we wanted to be certain that heritage evaluation uniquely predicted interaction intimacy, disclosure, and quality, independent of feelings of how one was being personally evaluated. Additionally, we felt it was also important to rule out the possibility that the characteristics of one's interaction partner were driving the positive effects of heritage evaluation. It may be that the reason culturally affirming interactions are associated with enhanced intimacy, disclosure, and quality is that such interactions are more likely to occur with ingroup members, or with people whom one is close to. Therefore, interactions were coded as being either with a member of one's ingroup (another member of one's heritage culture) or with an outgroup member (i.e., English-Canadian, French-Canadian, or other). Interactions that occurred with family members and friends were distinguished from those with employers, coworkers, or acquaintances. The analyses were then repeated, controlling for personal evaluation, as well as the ingroup/outgroup and close/not close distinctions. In all cases, heritage evaluation was still a significant predictor of intimacy $\left[\gamma_{10}=.10, p=.01\right.$; grand mean for intimacy $\left.\left(\gamma_{00}\right)=5.22\right]$, personal disclosure $\left[\gamma_{10}=\right.$ $.08, p<.01$; grand mean for personal disclosure $\left.\left(\gamma_{00}\right)=4.69\right]$, partner disclosure $\left[\gamma_{10}=.09, p=.01\right.$; grand mean for partner disclosure $\left.\left(\gamma_{00}\right)=4.86\right]$, and quality $\left[\gamma_{10}=\right.$ $.23, p<.001$; grand mean for quality $\left.\left(\gamma_{00}\right)=5.61\right]$. This suggests that heritage evaluation has an influence on the characteristics of one's interactions regardless of one's feelings of personal evaluation, the ethnicity of one's interaction partner, or the relationship one has with him or her.

\section{Cultural Chameleonism and Public CSE as Moderators of Heritage Evaluation}

Analyses were conducted to test the hypothesis that the Level 2 variables of cultural 
chameleonism and public CSE would moderate the effects of heritage evaluation on intimacy, personal disclosure, partner disclosure, personal evaluation, and interaction quality. The generalized model is presented in Table 2.

Both cultural chameleonism and public CSE significantly moderated the effects of heritage evaluation on intimacy and personal evaluation. However, chameleonism was the only significant moderator of personal and partner disclosure, and neither chameleonism nor public CSE moderated the effects of heritage evaluation on interaction quality. Including chameleonism and public CSE as moderators enabled us to account for $24.31 \%$ of the between-person variability of relationships between intimacy and heritage evaluation, $11.02 \%$ of the between-person variability of relationships between personal disclosure and heritage evaluation, $13.98 \%$ of the between-person variability between partner disclosure and heritage evaluation, and $32.02 \%$ of the between-person variability between personal evaluation and heritage evaluation. Thus, individuals who adopt a chameleon-like approach to managing their multicultural identity and who were low in public CSE were more likely to behave less intimately and feel that they personally were more negatively evaluated in interactions when their heritage culture was poorly evaluated. However, perceived personal and partner disclosure in response to a negative cultural evaluation was solely moderated by whether or not the individual had a chameleon-like identity. Finally, neither chameleonism nor public CSE was a significant direct predictor of mean levels of intimacy, personal disclosure, partner disclosure, personal evaluation, or quality.

\section{Discussion}

The primary goal of this study was to consider the effect of having a multicultural identity on one's daily social interactions. Our findings indicated that multicultural participants who adopted a chameleon-like

TABLE 2 Conditional Models for Each of the Outcome Variables (i.e., Intimacy, Self-Disclosure, Other Disclosure, Personal Evaluation, and Quality), With Chameleonism and Public Collective Self-Esteem (CSE) as a Level 2 Predictor of Means and Moderators of Slopes

\begin{tabular}{|c|c|c|c|c|c|c|c|c|c|c|}
\hline \multicolumn{11}{|c|}{ 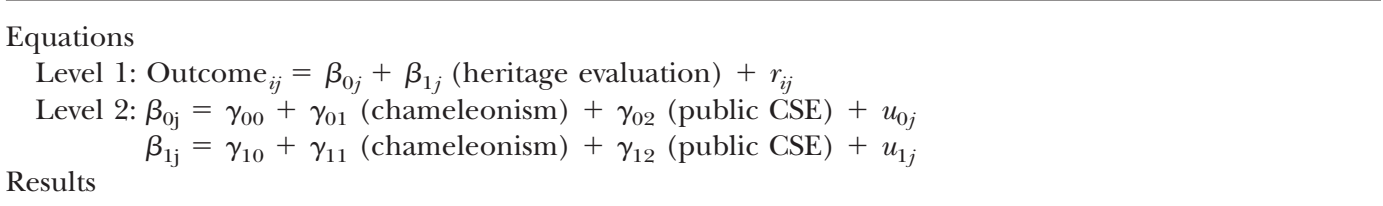 } \\
\hline \multirow[b]{3}{*}{ Fixed effect } & \multicolumn{10}{|c|}{ Outcomes } \\
\hline & \multicolumn{2}{|c|}{ Intimacy } & \multicolumn{2}{|c|}{$\begin{array}{l}\text { Personal } \\
\text { disclosure }\end{array}$} & \multicolumn{2}{|c|}{$\begin{array}{c}\text { Partner } \\
\text { disclosure }\end{array}$} & \multicolumn{2}{|c|}{$\begin{array}{l}\text { Personal } \\
\text { evaluation }\end{array}$} & \multicolumn{2}{|c|}{ Quality } \\
\hline & Coefficient & $p$ & Coefficient & $p$ & Coefficient & $p$ & Coefficient & $p$ & Coefficient & $p$ \\
\hline \multicolumn{11}{|l|}{ Means as outcomes, $\beta_{0_{j}}$} \\
\hline Chameleonism $\left(\gamma_{01}\right)$ & $\begin{array}{r}4.19 \\
-0.00\end{array}$ & . .44 & $\begin{array}{l}4.00 \\
0.00\end{array}$ & .86 & $\begin{array}{r}4.02 \\
-0.00\end{array}$ & $\begin{array}{l}.001 \\
.94\end{array}$ & $\begin{array}{r}5.00 \\
-0.00\end{array}$ & .001 & $\begin{array}{l}5.12 \\
0.00\end{array}$ & $\begin{array}{l}.001 \\
.78\end{array}$ \\
\hline Public CSE $\left(\gamma_{02}\right)$ & -0.00 & .95 & 0.01 & .70 & -0.00 & .87 & 0.01 & .62 & 0.00 & .73 \\
\hline \multicolumn{11}{|l|}{ Slopes as outcomes, $\beta_{1 j}$} \\
\hline Intercept $\left(\gamma_{10}\right)$ & 0.26 & .001 & 0.27 & .001 & 0.22 & .001 & 0.33 & .001 & 0.36 & .001 \\
\hline Chameleonism $\left(\gamma_{11}\right)$ & 0.01 & .03 & 0.01 & .03 & 0.01 & .02 & 0.01 & .001 & 0.00 & .30 \\
\hline Public CSE $\left(\gamma_{12}\right)$ & -0.01 & .04 & -0.01 & .54 & -0.00 & .55 & -0.02 & .03 & -0.01 & .36 \\
\hline
\end{tabular}


approach to managing their cultural identities were more likely to feel that their heritage culture was not generally valued by others and they reported having lower wellbeing. Moreover, in their daily social interactions, how they perceived their heritage culture was being evaluated by their interaction partner played a central role in determining how they rated other aspects of their interactions. Overall, during interactions in which multicultural persons felt that their heritage culture was being positively evaluated, they were more likely to perceive the interaction as intimate, they disclosed more and perceived their interaction partner as more disclosing, they enjoyed the interaction more, and they were more likely to indicate that they felt personally accepted. Furthermore, we were able to expand on previous research (Crocker et al., 1994) by demonstrating that collective selfesteem had an impact on participant's wellbeing in their social interactions independent of personal esteem.

The results of this study also revealed that two personality factors, namely, cultural chameleonism and public collective self-esteem, seemed to predispose multicultural persons to be more reactive to how their heritage culture was perceived across all their interactions. Reactivity was evidenced in their accentuated reduction in intimacy and disclosure, as well as in increased feelings of personal rejection, when they felt that their heritage culture was being negatively evaluated. It is particularly interesting that cultural chameleons and participants with low public CSE showed more disruptions in the intimacy of their social behavior when they felt their culture was devalued. Extensive research and theory has suggested that the experience of intimacy is essential to satisfying social relationships (Reis, 1990). Future researchers need to address whether the reduced intimacy experienced by cultural chameleons and individuals with low public CSE is an adaptive response to dealing with actual discrimination from their interaction partner or if instead these individuals are being rejection sensitive, that is, anxiously anticipating and strongly reacting to rejection from ambiguous cues (Downey \& Feldman, 1996).

The finding that cultural chameleonism and public CSE did not moderate the effects of heritage evaluation on quality was somewhat unexpected. Further research is needed to clarify this relationship; however, it may be that although having an integrated identity or generally feeling that one's heritage culture is positively regarded may enable an individual to be less reactive in terms of how they behave in an interaction when they perceive their heritage culture is being negatively viewed, it may be less effective in inoculating the individual against the negative affective quality that such an interaction would foster. ${ }^{2}$

This study adds to the growing body of research on the way in which immigrants and ethnic minority individuals manage their multicultural identity by further demonstrating the pervasiveness of the impact of integrating or compartmentalizing one's identity. A chameleon-like identity has been associated with well-being deficits (Downie et al., 2004); this study replicated that finding and indicated that such an identity can hinder functioning in daily interactions. In addition, a separate line of research has

\footnotetext{
${ }^{2}$ It is important to note that Crocker and Major (1989) argued that perceiving that others are reacting negatively to one's heritage culture can have self-protective effects that will promote adjustment. The current results do not seem directly relevant to that work for two reasons. First, in the vast majority of interactions multicultural participants did not feel that their heritage culture was being rejected, unlike in Crocker and Major's studies in which rejection was directly manipulated. Second, most interactions that people have that last in excess of $10 \mathrm{~min}$ are with family members, friends and coworkers, unlike in the work of Crocker and Major in which the other person was someone they had never met. Rejection may have been more potent in these situations because participants were motivated to be valued and accepted by these people (Leary \& Baumeister, 2000). Whereas rejection by peripheral persons, for whatever reason, may be upsetting, or disturbing, it may still have no impact on self-esteem, if the person's need for belonging have been adequately met by significant others (Baumeister \& Leary, 1995).
} 
shown that the level of integration of one's identity impacts social cognition (BenetMartinez et al., 2002; Haritatos \& BenetMartinez, 2002). These studies have shown that Asian Americans presented with a prime for Asian culture will respond to a culturally discerning task in a manner congruent with the Asian prime, if they have an integrated identity. If they have a compartmentalized identity they will respond as though they had been primed with American culture. Benet-Martinez and colleagues (2002) proposed that bicultural individuals who have an unintegrated identity see cultural cues as being highly valenced. We suggest that this increased valence, which is associated with contrast effects in social cognitive responses (Benet-Martinez et al., 2002), leads multicultural individuals to see their social interactions as equally highly valenced. This study suggests that the valenced reaction of one's interaction partner to one's heritage culture has further implications for the individual's behavior in his or her daily interactions.

The present study has limitations. First, all of our measures in the interaction record were single-item measures which may limit the inferences we can draw from them. In particular, our single-item measure of heritage evaluation does not allow us to clearly distinguish between the experiences of being neglected, which may be experienced more passively, and being outright rejected, which may be seen as a more active process. Although sociometer theory contends that there is little difference between the experience of ambivalence or neutrality and rejection (Leary \& Baumeister, 2000), some developmental research suggests otherwise. Previous studies with children have demonstrated that rejected and neglected children differ in self-reported subjective distress (Asher, Parkhurst, Hymel, \& Williams, 1990) and later risks for maladjustment (Ollendick, Weist, Borden, \& Greene, 1992). Similarly, different outcomes might be obtained for multicultural individuals who feel that their cultural identity is being neglected as opposed to rejected.
A further limitation is that our sample was composed entirely of university students. However, developmental psychologists have noted that the ages of 18-25 are a critical period of "emerging adulthood" in which individuals must resolve the questions of "Who am I?" and "How do I want to act in the world?" (Arnett, 2002). In this regard it would seem that emerging multicultural adults are an ideal sample to explore the questions raised in this article. Finally, the study was carried out in Montreal, Quebec, Canada, a context that can be considered in itself bicultural with a majority French-Canadian culture thriving beside a traditional English-Canadian culture. Although this may be a unique cultural environment, we argue that it does not limit the generalizability of our basic finding that identifying with a minority culture poses additional challenges to the way a person organizes his or her identity and this has an impact on their social interactions. However, given that Canada is a country that has a multiculturalism policy that encourages immigrants and ethnic minority individuals to develop and maintain a bi- or multicultural identity, our findings may not replicate exactly for immigrants to countries that emphasize rapid assimilation to the host culture.

On the basis of the results obtained in this study, it seems clear that future researchers on bi- or multiculturalism need to further distinguish how a person who does identify with multiple social identities conceptualizes and enacts those identities. These results indicate that having a chameleon-like versus an integrated multicultural identity has an impact on both the general well-being and the daily functioning of multicultural individuals. Consideration should also be given to whether multiracial persons who simultaneously identify with each of their racial groups also exhibit this same pattern of integration or chameleonism with similar effects. Although multiracial individuals still represent a small minority of the population, mixed unions are becoming more common, with the number of such couples increasing by 35\% between 1991 
and 2001 in Canada alone ("Study: Mixed Unions," 2005, June 8). As such, researchers will need to devote more attention to this diversified, growing population.

In conclusion, in the present study we highlight the centrality of the heritage culture in the daily interactions of multicultural individuals. The perception that one's heritage group was being positively viewed was associated with an increase in the intimacy, disclosure, feelings of personal acceptance, and enjoyment of the interaction. Moreover, having a chameleon-like identity or low public CSE seems to predispose multicultural people to be more reactive to perceived rejection of their heritage culture. These findings suggest that the pattern of immigrants' social interactions may be contingent on how accepting versus rejecting their partners are of their heritage culture.

\section{References}

Arnett, J. J. (2002). The psychology of globalization. American Psychologist, 57, 774-783.

Asher, S. R., Parkhurst, J. T., Hymel, S., \& Williams, G. A. (1990). Peer rejection and loneliness in childhood. In S. R. Asher, \& J. D. Coie (Eds), Peer rejection in childhood (pp. 253273). Cambridge, England: Cambridge University Press.

Baumeister, R., \& Leary, M. R. (1995). The need to belong: Desire for interpersonal attachments as a fundamental human motivation. Psychological Bulletin, 117, 497-529.

Benet-Martinez, V., Leu, J., Lee, F., \& Morris, M. W. (2002). Negotiating biculturalism: Cultural frame switching in biculturals with oppositional versus compatible cultural identities. Journal of Cross-Cultural Psychology, 33, 492-516.

Census figures show dramatic growth in Asian, Hispanic populations. (2000, August 30). CNN. Retrieved January 13, 2006, from http://archives.cnn.com/2000/US/08/30/ minority.population.index.html

Census of population: Immigration, birthplace and birthplace of parents, citizenship, ethnic origin, visible minorities and Aboriginal peoples. (2003, January 21). The Daily. Retrieved January 13, 2006, from http://www.statcan.ca/ Daily/English/030121/d030121a.htm

Chirkov, V., Ryan, R. M., Kim, Y., \& Kaplan, U. (2003). Differentiating autonomy from individualism and independence: A self-determination theory perspective on internalization of cultural orientation, gender and well-being. Journal of Personality and Social Psychology, 84, 97-110.

Crocker, J., \& Luhtanen, R. (1990). Collective self-esteem and ingroup bias. Journal of Personality and Social Psychology, 58, 60-67.

Crocker, J., Luhtanen, R., Blaine, B., \& Broadnax, S. (1994). Collective self-esteem and psychological well-being among White, Black, and Asian college students. Personality and Social Psychology Bulletin, 20, 503-513.

Crocker, J., \& Major, B. (1989). Social stigma and self-esteem: The self-protective properties of stigma. Psychological Review, 96, 608-630.

Deci, E. L., \& Ryan, R. M. (2000). The "what" and "why" of goal pursuits: Human needs and the self-determination of behavior. Psychological Inquiry, 11, 227-268.

Downey, G., \& Feldman, S. I. (1996). Implications of rejection sensitivity for intimate relationships. Journal of Personality $\mathcal{E}$ Social Psychology, 70, 1327-1343.

Downie, M., \& Koestner, R. (2004, June). The centrality of heritage acceptance in the daily interactions of tricultural individuals. Paper presented at the 65th Annual Convention for the Canadian Psychological Association, St. John's, Newfoundland, Canada.

Downie, M., Koestner, R., ElGeledi, S., \& Cree, K. (2004). The impact of cultural internalization and integration on well being among tricultural individuals. Personality and Social Psychology Bulletin, 30, 305-314.

Haritatos, J., \& Benet-Martinez, V. (2002). Bicultural identities: The interface of cultural, personality, and socio-cognitive processes. Journal of Research in Personality, 36, 598-606.

Kreft, I., \& de Leeuw, J. (1998). Introducing multilevel modeling. Thousand Oaks, CA: Sage.

LaFromboise, T., Coleman, H. L. K., \& Gerton, J. (1993). Psychological impact of biculturalism: Evidence and theory. Psychological Bulletin, 114, 395-412. 
Leary, M. R. (1999). Making sense of self-esteem. Current Directions in Psychological Science, 8, 3235.

Leary, M. R., \& Baumeister, R. F. (2000). The nature and function of self-esteem: Sociometer theory. In, M. P. Zanna (Ed.), Advances in experimental social psychology (Vol. 32, pp. 1-62). San Diego, CA: Academic Press.

Longitudinal survey of immigrants to Canada. (2005, September 4). The Daily. Retrieved January 13, 2006, from http://www.statcan.ca/Daily/English/030904/ d030904a.htm

Luhtanen, R., \& Crocker, J. (1992). A collective self-esteem scale: Self-evaluation of one's social identity. Personality and Social Psychology Bulletin, 18, 302-318.

Nezlek, J. B. (2003). Using multilevel random coefficient modeling to analyze social interaction diary data. Journal of Social and Personal Relationships, 20, 437-469.

Ollendick, T. H., Weist, M. D., Borden, M. G., \& Greene, R. W. (1992). Sociometric status and academic, behavioral, and psychological adjustment: A five-year longitudinal study. Journal of Consulting and Clinical Psychology, 60, 80-87.

Raudenbush, S. W., \& Bryk, A. S. (2002). Hierarchical linear models: applications and data analysis methods (2nd ed.). Thousand Oaks, CA: Sage.

Reis, H. T. (1990). The role of intimacy in inter- personal relations. Journal of Social E Clinical Psychology, 9, 15-30.

Roccas, S., \& Brewer, M. B. (2002). Social identity complexity. Personality and Social Psychology Review, 6, 88-106.

Ryan, R. M., \& Deci, E. L. (2002). On assimilating identities to the self: A self-determination theory perspective on internalization and integrity within cultures. In M. S. Leary \& J. P. Tangney (Eds.), Handbook of self and identity (pp. 255-273). New York: Guilford.

Ryff, C. D., \& Keyes, C. L. M. (1995). The structure of psychological well-being revisited. Journal of Personality and Social Psychology, 69, 719-727.

Sheldon, K. M., Ryan, R. M., Rawsthorne, L. J., \& Ilardi, B. (1997). Trait self and true self: Cross-role variation in the Big-Five personality traits and its relations with psychological authenticity and subjective well-being. Journal of Personality and Social Psychology, 73, 13801393.

Study: Canada's Visible minority population in 2017. (2005, March 22). The Daily. Retrieved January 13, 2006, from http://www.statcan. ca/Daily/English/050322/d050322b.htm

Study: Mixed unions. (2004, June 8). The Daily. Retrieved January 17, 2006, from http://www.statcan.ca/Daily/English/040608/ d040608b.htm

Wheeler, L., \& Nezlek, J. (1977). Sex differences in social participation. Journal of Personality and Social Psychology, 54, 323-333. 